\title{
Review on research and application of stainless steel reinforced concrete
}

\author{
Li GU $^{1, a}$, Xian Hong MENG ${ }^{1}$ \\ ${ }^{1}$ Department of Civil Engineering, Shenyang Jianzhu University, Shenyang, China
}

\begin{abstract}
For ordinary reinforced under corrosion environment corrosion problems and analysis the main factors affecting ordinary steel corrosion, proposed stainless steel bar rust and corrosion resistance advantages, introduce the related properties of the stainless steel reinforced, combined with the research status of domestic and international stainless steel bar, put forward the research and engineering application of stainless steel rebar for the related problems and direction, the prospects and development of stainless steel reinforced put forward suggestions.
\end{abstract}

\section{Introduction}

Currently most practical engineering, ordinary carbon reinforced concrete in a non-extreme environments can maintain good performance, the design life of the structure in the basic need for maintenance, when the bar is used in bridge engineering, marine engineering, underground engineering, high corrosion special environment, reinforced concrete often do not meet the design life, structural damage and destruction appeared, even failure. Corrosion of steel structure led to a serious degradation of performance, but also affect the safety and durability of the structure. Durability of reinforced concrete structures become an urgent problem.

Traditional reinforced anti-corrosion method (galvanized steel surface; use of high-strength concrete; concrete protective layer thickness increases) can not be avoided under a special environment of long-term corrosion of steel and structural performance degradation. The use of stainless steel instead of ordinary carbon steel with its excellent anti-corrosion resistance, machinability, high temperature impact resistance can be solved to a large extent from the steel corrosion problem.

Some foreign countries and has been used in the actual project for stainless steel has been more systematic design manual. In 2004, China in the "durability of concrete structures Design and Construction Guidelines" provisions, In particularly severe corrosive environment, to ensure that more than one hundred years of service life of the special important projects, can be used stainless steel. Our country is still a lack of systematic instruction for stainless steel, the stainless steel has caused tremendous obstacles in the development and application in china.

\footnotetext{
a Corresponding author: 799907264@qq.com
}

\section{The reinforced concrete problems}

\section{1 reasons for corrosion of ordinary steel bars}

There are many factors that cause the failure of the structure, the corrosion of steel bars is a key factor, and the main cause of the corrosion of the common steel bar is the accumulation of internal damage and the special environment.

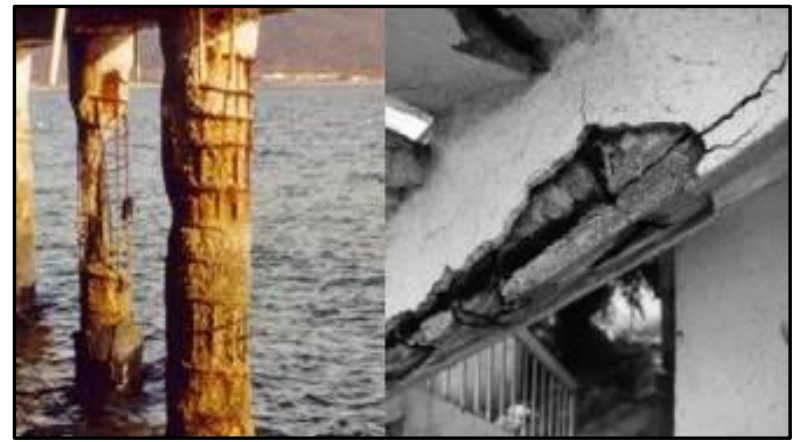

Figure 1. The steel corrosion phenomena

Due to the concrete structure with cracks, in the marine environment of high corrosion environment, environment of water, chloride and salt and other substances through the concrete surface cracks or voids, towards the gradual spread of the concrete, reduce the concrete alkaline. At the same time, reinforced the original compact passivation film was damage caused by steel corrosion, corrosion products generated by the enable the reinforcement volume expansion, aggravate crack expansion, more corrosive substances invasion within the concrete, accelerate the steel corrosion, 
neutralization of concrete and the crack development.Since the bonding properties of rust matter, between steel and concrete fell, increasing the relative degree of slip, with the internal damage of development and accumulation, and ultimately lead to spalling of concrete steel corrosion.

In combination with the external conditions such as air, temperature and humidity, the acid and alkali salt through the concrete surface pore into the concrete inside and between the reinforcement of electrochemical corrosion, the corrosion damage is very strong, veryfast. Electrochemical corrosion usually occurs in high chloride high salt environment, such as: the marine environment, the use of de-icing salt deicing salt bridges, roads, high soil salinity environment and so on. External special environment allows ordinary carbon steel is difficult to resist corrosion, resulting in damage and destruction of the structure.

Corrosion of steel is the result of special external environment and internal damage to the role. External factors for the steel corrosion provides objective criteria such as: temperature and humidity, salinity content of the acid environment of the material is high, the role of structural fatigue load and the like. Internal factors aggravate the damage accumulation, for example: the concrete carbonation, crack expansion, corrosion of the accumulation of steel, such as volume expansion.

\subsection{Methods to improve the durability of reinforced concrete structures}

In the rational design and construction conditions, to prevent steel corrosion in order to ensure the safety of the structure, increasing the durability of the structure, thereby improving the service life of reinforced concrete. The main method of increasing the structural durability of steel and concrete can be from two aspects.

(1) in the high corrosion environment, the metal coating is commonly used in the measure, commonly used in the coating metal are: zinc, nickel, chromium, etc. For the purposes of ordinary steel, galvanized steel is anodic coating has excellent electrochemical protection; single nickel-plated steel is common for cathodic coating, and high porosity, corrosion resistance is poor; chrome-plated steel have good chemical stability, with a base, sulfide, nitric acid and other non-reactive.

(2) increasing the thickness of concrete protective layer or adding covering layer, but simply improving the thickness of concrete protective layer will not have a great improvement on the corrosion resistance of steel reinforcement, and the increase of thickness will increase the cost of the project. The use of high strength concrete is also commonly used to prevent steel corrosion method,with its characteristics of high compactness, reduce erosion damage to the reinforcement material.

Using galvanized steel, highstrength concrete,increasing the thickness of the protective layer measures are unable to complete requirements of reinforcement corrosion, while the use of corrosion-resistant reinforcement(such as: stainless steel reinforced) can effectively resist the corrosion factors of the environment, to increase the durability of the structure.

\section{3 stainless steel research status at China and abroad}

\section{1 stainless steel performance}

Stainless steel material has high chemical stability, especially in high corrosion environment, the superior corrosion resistance of stainless steel has become the focus of attention of researchers.

Stainless steel mainly containing chromium, nickel, molybdenum and other alloying elements, which vary depending on the chromium content in stainless steel, stainless steel and acid corrosion resistance will vary, chromium content in steel should be maintained at between $11 \%$ to $30 \%$, only stainless steel with acid corrosion resistance, rather than the chromium content, the better, the chromium content in the usual sense of the stainless steel should be greater than $10.5 \%$, equal to the carbon content of less than $1.2 \%$.

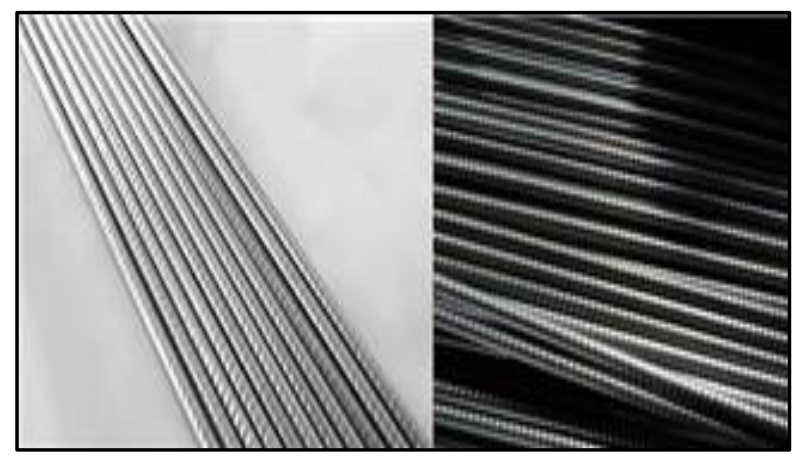

Figure 2. Stainless steel

Alloying elements nickel and molybdenum also improve its corrosion resistance, but play a major role is the chromium, and nickel element for strengthening inter-group if the microscopic crystal structure of stainless steel, to ensure its mechanical properties and mechanical properties.

In addition to these three elements, it will join the stainless steel, silicon, titanium, magnesium, niobium, aluminum and other elements, addition of these alloying elements can not only strengthen the stainless steel corrosion resistance to acids, reduce the carbon content, while improving to some extent stainless steel plasticity, weldability, toughness and processability, making it more suitable used in engineering practice. Holding chromium, nickel and other elements content showed a certain proportion, reduce the carbon content, the better the performance of the corrosion resistance of stainless steel.

Table 1. Mechanical properties of stainless steel $(304,316,2205)$

\begin{tabular}{cccc}
\hline $\begin{array}{c}\text { performance } \\
\text { parameter }\end{array}$ & $\mathbf{3 0 4}$ & $\mathbf{3 1 6}$ & $\mathbf{2 2 0 5}$ \\
\hline $\begin{array}{c}\text { elastic } \\
\text { modulus }(\mathrm{GPa}) \\
\text { chromium } \\
\text { content }(\%)\end{array}$ & 193 & 193 & 190 \\
\hline
\end{tabular}




\begin{tabular}{cccc}
\hline $\begin{array}{c}\text { yield } \\
\text { limit(MPa) } \\
\text { tensile }\end{array}$ & $\geq 205$ & $\geq 205$ & $\geq 450$ \\
strength(MPa) & $\geq 520$ & $\geq 520$ & $\geq 620$ \\
Elongation(\%) & $\geq 40$ & $\geq 40$ & $\geq 25$ \\
\hline
\end{tabular}

\subsection{Status of foreign steel Stainless Steel}

Stainless steel study abroad for relatively large, especially in the United States, Britain and other stainless steel has been included in the list of steel reinforced concrete, while in some areas of high corrosion and high durability requirements of the building project has been the practical application.

T.Zhongand Kim J. R. Rasmussen use three basic Ramberg - Osgood Parameters of ferritic stainless steel stress - strain curve, they found that the current based on Rasmussen (2003) and Wang (2014) stress-strain model is not suitable ferritic stainless steel or cold-formed hollow sections by cutting ferritic stainless steel tensile test specimens revised model, and the model for yield stress $[250,550] \mathrm{MPa}$ ferritic stainless steel has good predictive results.

Siebren J. DeJong, Patrick J.Heffernan, Colin MacDougall through a series of constant amplitude and periodicity overload test to study the MMFX and 316LN stainless steel in a corrosive environment, fatigue resistance, and found MMFX and 316LN stainless steel have a good super periodicity load corrosion fatigue performance, Determine the current steel fatigue design criteria can be used MMFX and 316LN stainless steel, features and functions of the two materials fatigue limit in corrosive environments periodic overload within $250 \mathrm{Mpa}$ range, while traditional low-alloy steel exhibited no fatigue limit

M. Nakajima, M. Akita, Y. Uematsuc, K. Tokaji study of type 304 stainless steel fatigue performance problems in $3 \% \mathrm{NaCl}$ solution and $15 \%, 30 \%$ and $60 \%$ tensile pre-strain samples effect, research shows under these conditions, the fatigue strength increases with prestrain increases, stainless steel fatigue strength under these conditions were: $280 \mathrm{MPa}, 320 \mathrm{MPa}$ and $320 \mathrm{Mpa}$, in the role of the air sample of $15 \%, 30 \%$ and $60 \%$ pre-stretch after the strain fatigue strength are: $320 \mathrm{MPa}, 420 \mathrm{MPa}$ and 480Mpa; martensitic transformation with the prestrain increases; type 304 stainless steel corrosion fatigue behavior of the affected martensite.

Mesquita, Thiago J, Chauveau, Eric, Mantel, Marc, who studied in austenitic, ferritic, duplex stainless steel corrosion properties of Mo added Elements of stainless steel in an alkaline environment, identifying three stainless steel corrosion pitting and passivation characteristics of a bad environment.

Shayan. A, Xu. A study by chloride contamination of the concrete and stainless steel welding injury problems, has been reinforced stainless steel lap can effectively resist corrosion damage, the chlorine content in the appropriate environment, low-carbon by galvanic corrosion of steel is negligible, electrochemical properties were studied exposure to chloride contaminated concrete steel reinforcing bar. Further Shayan, A, Xu, A also studied restoration and stainless steel corrosion in concrete properties, the conclusion is: Stainless steel can effectively prevent the concrete structure due to key parts of chloride-induced corrosion damage.

Schiegg. Y, Voute. CH, Peter. H, Urlau. U study of ordinary carbon steel, duplex stainless steel (1.4462) and chromium steel (1.4003) for different chloride concentration, $\mathrm{PH}$ value and other test conditions, has been reinforced specimen corrosion test data presented stainless steel corrosion initiation and propagation in concrete structures conclusions.

\section{3 research status of stainless steel in China}

Since the domestic late start, so a lot of research on stainless steel still at the primary stage.

G.X.Zhang,Y.Zhangby stainless steel reinforced concrete slab and reinforced concrete slab of static test and fatigue test, it is concluded that the same conditions stainless steel reinforced concrete slabs than ordinary reinforced concrete plate ultimate bearing capacity increase $13.8 \%$, stainless steel bar specimen failure strain is 5.31 times that of ordinary steel, cross deflection reduced $13.03 \%-30.27 \%$, tensile reinforcement strain reduced $16.69 \%-46.76 \%$, concrete strain decreased $8.9 \%-29.63 \%$.

G.X. Zhang, Y.H. Xu, Z. Ding.They studied the flexural performance of the stainless steel reinforced concrete beams. The test results show that the tensile strength of the stainless steel reinforced than its yield strength; under the same conditions, the deflection and the maximum crack width of the stainless steel reinforced concrete beams are larger than that of the ordinary reinforced concrete beams; the calculation of the maximum crack width can be designed according to the current specification, and the deflection calculation is based on the American ACI code.

H.X. Yuan, Y.Q. Wang, Y.J. Shi.Their application in the building structure of stainless steel, the prospect is described, the stainless steel to improve the durability of the structure, reduce the corrosion rate of reinforcement and maintenance and reinforcement cost advantage.

G.J.Van den Berg, A.H. Liang analysis of ordinary steel corrosion reasons, the use of reinforced concrete and steel reinforced concrete comparative tests, indicating that the stainless steel good corrosion resistance and which has a yield limiting.

H.C. Zhu, J. Yao study the mechanical properties of stainless steel and stainless steel constitutive model drawn steel stress-strain relationship is nonlinear and anisotropic conclusion, through simulation and experimental results show that the use Quach model component designed to meet the requirements.

G.X. Zhang, F. Zhao, Z.H. Zhang, H.Y. Zhang, X.W. Zhou, D.J. Raoby the pseudo static experimental study on seismic performance of steel reinforced concrete beams. They made of stainless steel reinforced concrete beams under low cyclic loading, through elasticity, yield enhancement, strength degradation stage, and stainless steel reinforced concrete beam deformation is large still 
has a large bearing capacity reserves. Stainless steel ductility is good, full hysteresis curve, the total energy consumption and energy dissipation coefficient is 2.36-4.25 times that of ordinary reinforced concrete beams and 1.12-2.63 times. Capacity, yield strength, ductility, energy dissipation rate increased with the stirrup. Stainless steel reinforced concrete beams better seismic performance.

Table 2. Stainless steel reinforced concrete engineering

\begin{tabular}{|l|l|l|l|}
\hline project name & country & $\begin{array}{l}\text { Stainless steel } \\
\text { models }\end{array}$ & position \\
\hline Progreso Pier Bridge & Mexico & AISI304 & \\
\hline AbandoibataddBridge & Spain & 2205 & Millennium \\
\hline $\begin{array}{l}\text { York } \\
\text { Bridge }\end{array}$ & Britain & 2205 & $\begin{array}{l}\text { arched } \\
\text { beams } \\
\text { and } \\
\text { sling }\end{array}$ \\
\hline Sheikh Zayed Bridge & UAE & EN1.4462 & $\begin{array}{l}\text { lower } \\
\text { portion } \\
\text { ofbridge }\end{array}$ \\
\hline Britain Hall & Britain & $316 \mathrm{~L}$ & \\
\hline $\begin{array}{l}\text { Herringbone } \\
\text { bridge }\end{array}$ & Germany & 0Cr17Ni12Mo2 & \\
\hline $\begin{array}{l}\text { Auckland } \\
\text { transmission tunnel }\end{array}$ & $\begin{array}{l}\text { new } \\
\text { Zealand }\end{array}$ & 0Cr18Ni9 & \\
\hline Stonecutters Bridge & China & 2205 & \\
\hline $\begin{array}{l}\text { Hong } \\
\text { Kong-Zhuhai-Macao } \\
\text { Bridge }\end{array}$ & China & 2205 & \\
\hline
\end{tabular}

\section{4 problems}

Stainless steel with superior corrosion resistance can overcome an ordinary carbon steel corrosion problems in highly corrosive environments and durability and safety of structures have special requirements, which has a broad space for development. However, studies on stainless steel is still not perfect, which gives practical application to bring obstacles. Where the main problems are:

(1) The key factors that hinder the development of stainless steel is its higher initial cost of stainless steel per ton than ordinary steel about 6-10 times, but if considering the whole life cycle cost structure, stainless steel has a great advantage, ordinary carbon steel is usually the life of about 23 years, while the stainless steel does not require post-maintenance. Structures within their service period, maintenance expenses strengthening reinforced concrete structures is much higher than stainless steel.

In was built in the 1940s in Mexico Progreso Pier Bridge as an example, the use of 200 tonnes of AISI304 grade stainless steel, stainless steel exhibits good corrosion resistance and durability, but also during their service, almost no investment in maintenance costs, built in the 1980s, ordinary steel bridge in the marine environment under the long-term erosion occurred collapsed. To solve the high cost of the initial problem, you can take the stainless steel combination of ordinary carbon steel structural measures in key positions, and to improve the durability of the structure, the purpose of reducing ongoing maintenance costs.

(2) For high corrosive environmental conditions and long-term effects of fatigue loading structure (such as: sea-crossing bridges, offshore drilling platforms), the mechanical properties of stainless steel under fatigue cyclic loading conditions to determine the damage and failure mechanism and member attenuation of structural fatigue life by the effects of corrosion remains a key problem.

(3) damage evolution under study fatigue and corrosion both coupling concrete structure coupling analysis of the cumulative conditions under both structural damage, rather than a single consideration of fatigue or corrosion conditions on structural damage. Coupling effect on stainless steel reinforced concrete deterioration development.

(4) usually test difficult realization of component random amplitude fatigue loading, and many of the component functions of constant load or fatigue load. The actual load is difficult to determine the size and direction of research, amplitude fatigue loading has more practical significance to study the dynamic characteristics of stainless steel.

(5) Stainless steel and concrete bonding properties of the two materials, stainless steel with regard to corrosion environment fatigue failure mechanism of bond between steel and concrete, a clear test pieces in various stages of destruction anchoring force of the proposed bond stress relaxation law.

\section{Conclusion}

The corrosion resistance of stainless steel can have gradually displayed in engineering practice,for the development of marine engineering projects to improve durability under high corrosive environment structure has broad application prospects.

Meanwhile, Retrofitting existing buildings, structures replace key parts, extended service life of the structure, reduce maintenance costs structure has important practical significance. To solve the traditional steel corrosion under extreme environmental conditions is difficult to guarantee the life of structures and other issues of great reference value.Moreover,the country building a resource-saving and environment-friendly strategy has a positive role in promoting.Theoretical and experimental research carried stainless steel reinforced concrete, stainless steel rebar in the promotion of the use of engineering practice is very necessary.

\section{Acknowledgements}

This work is financially supported by National High-tech R\&D Program (863 Program)(2015AA03A502-3). 


\section{References}

1. G.J.VandenBerg,A.H.Liang.Architecture Technology.J.31.105-107(2000)

2. G.X. Zhang,M.M.Wu.Journal of Foshan University (Natural Science).J.24.10-13(2006)

3. M.Nakajima,M. Akita,Y. Uematsu,K. Tokaji. Procedia Engineering.J.2.323-330(2010)

4. Siebren J. DeJong,Patrick J.Materials In Civil Engineering.J.21.1-9(2009) 